milk powder. No abnormalities in stool tryptic activity, plasma protein levels, or intramural ganglionic plexuses were found. In four of the children carbohydrate- and proteinabsorption studies were carried out. These showed a temporary deficiency of absorption of sugars but a persistent deficiency of protein absorption, though this absorption defect was subclinical. It is suggested, therefore, that obstruction by milk curd will be encountered only when early high-caloric feeding is instituted in babies who have a subclinical deficiency in their capacity for absorbing proteins and aminoacids.

While it would be wrong to hold the occasional adverse result as an argument against the early feeding of both the premature and the full-term baby, this series of cases once more emphasizes the disadvantages of artificial feeds as distinct from breast milk, and also emphasizes the point that bile-stained vomiting in the newborn, whether it is within the first two or three days or in the first two or three weeks of life, indicates intestinal obstruction until proved otherwise.

\section{Lung Scanning}

Radioisotope scanning of the lungs has become widely used since it was introduced by G. V. Taplin and his colleagues in 1964. ${ }^{1}$ Radioactive particles, measuring 20-100 $\mu$ in diameter, are given intravenously and become impacted in the small pulmonary arterioles. The distribution of these particles, which is proportional to the blood flow in the pulmonary arteries, at the time of injection, is readily shown by scintillation scanning. The radiation received by the lungs using particles of human serum albumin labelled with Technetium- $-99^{\mathrm{m}}$ is small, being comparable to that received during a routine chest radiøgraph.

Lung scanning is of most value in the diagnosis of pulmonary embolism, ${ }^{2-5}$ particularly in its early stages. Characteristically, it shows defects in perfusion of the lungs, which are usually multiple and often more extensive than would be expected clinically or radiologically. Lung scans have also been carried out in many other respiratory and cardiac conditions such as carcinoma of the bronchus, ${ }^{6-8}$ chronic bronchitis, emphysema, ${ }^{9}$ asthma, ${ }^{10}$ pneumonia, tuberculosis, ${ }^{11}$ bronchiectasis, sarcoidosis, fibrosing alveolitis, chronic rheumatic heart disease, ${ }^{12}$ congenital heart disease, ${ }^{2}$ and congestive heart failure. In all these conditions the pattern of perfusion is disturbed, and any of them must be borne in mind in the differential diagnosis of the chest radiograph and the lung scan carried out for suspected pulmonary embolism. In particular, chronic bronchitis and emphysema account for an increasing incidence of abnormal scans in older patients.

Comparison of lung scans with the more hazardous ${ }^{13}$ but definitive procedure of selective pulmonary angiography shows a good correlation, particularly when the emboli are in the main, lobar, or segmental branches of the pulmonary arteries. ${ }^{1415}$ The more peripherally an embolus is situated, the more difficult it becomes to show by angiography, whereas such emboli produce readily visible defects on scanning. ${ }^{16}$ When separate anterior and posterior scans are made few emboli are missed, and lateral scans will sometimes show additional unexpected defects. ${ }^{17}$

- British Medical fournal, 1965, 2, 6.

- British Medical fournal, 1969, 1, 459.

- Smallpeice, V., and Davies, P. A., Lancet, 1964, 2, 1349.

- British Medical fournal, 1969, 2, 203.

- Pugh, R. J., Lancet, 1968, 1, 644.
Unexpectedly large defects in perfusion may be found in carcinoma of the bronchus, ${ }^{6-8}$ and it is important to know their extent when thoracotomy is contemplated. The relative perfusion of each lung may be estimated from a lung scan ${ }^{18-20}$ and the resectability of a tumour can largely be determined from the reduction in perfusion of the affected lung, for this is closely related to involvement of the pulmonary vessels at the hilum. ${ }^{21}$ Furthermore, lung scans may occasionally indicate the likely site of a bronchial carcinoma in that small but diagnostically embarrassing group of patients with malignant cells in their sputum but normal chest radiographs and normal findings on bronchoscopy. Finally, F. R. Beerel and his colleagues have suggested that lung scanning is a satisfactory routine method for assessing the pulmonary vasculature in emphysema. ${ }^{22}$

The outstanding advantages of lung scanning are the safety, simplicity, and speed with which the pattern of pulmonary arterial perfusion can be determined, even in severely ill patients. Against this must be set the pitfalls in interpretation in the early postoperative period, and in the presence of chronic obstructive airways disease or cardiomegaly. Another practical disadvantage is that radioactive particles labelled with Technetium- $99^{\mathrm{m}}$ or Indium- $113^{\mathrm{m}}$ must be prepared locally each day lung scans are required, as both isotopes have short half-lives- 6 hours and $1 \cdot 7$ hours, respectively. Nevertheless, the cost of a lung scan is no greater than that of other scans, such as liver or blood pool scans, in which the radioisotope must be prepared in a special form in order to localize in the structures required.

Radioactive macroaggregates of human serum albumin labelled with Iodine-131 are now prepared commercially in Britain. Though scans made with this material expose the patient to more radiation, take longer, and are technically less satisfactory than the scans made with Technetium- $99^{\mathrm{m}}$ or Indium-113 $\mathrm{m}$, the availability of Iodine-131-labelled

1 Taplin, G. V., Johnson, D. E., Dore, E. K., and Kaplan, H. S., fournal of Nuclear Medicine, 1964, 5, 259.

2 Tauxe, W. N., Burchell, H. B., and Black, L. F., Mayo Clinic Proceedings, 1967, 42, 473.

s Sabiston, D. C., and Wagner, H. N., Annals of Surgery, 1964, 160, 575.

- Haynie, T. P., Hendrick, C. K., and Schreiber, M. H., fournal of Nuclear Medicine, 1965, 6, 613.

- Quinn, J. L., Whitley, J. E., Hudspeth, A. S., and Prichard, R. W., Radiology, 1964, 82, 315.

Hatch, H. B., Maxfield, W. S., and Ochsner, J. L., fournal of Thoracic and Cardiovascular Surgery, 1965, 50, 634.

7 Wagner, H. N., Lopez-Majano, V., Tow, D. E., and Langan, J. K., Lancet, 1965, 1, 344.

- Garnett, E. S., Goddard, B. A., Fraser, H. S., and MacLeod, W. M., British Medical fournal, 1968, 2, 209.

Lopez-Majano, V., Tow, D. E., and Wagner, H. N., fournal of the American Medical Association, 1966, 197, 81.

10 Mishkin, F. S., and Wagner, H. N., Fournal of the American Medical Association, 1968, 203, 1019.

1 Lopez-Majano, V., Wagner, H. N., Tow, D. E., and Chernick, V., fournal of the American Medical Association, 1965, 194, 1053.

12 Friedman, W. F., and Braunwald, E., Circulation, 1966, 34, 363.

13 Sabiston, D. C., Durham, N. C., and Wagner, H. N., fournal of Thoracic and Cardiovascular Surgery, 1965, 50, 339.

14 Fred, H. L., Burdine, J. A., Gonzalez, D. A., Lockhart, R. W. Peabody, C. A., and Alexander, J. K., New England fournal of Medicine, 1966, 275, 1025.

15 Bell, T. K., Ferguson, R., McIlrath, E. I., and Weaver, J. A., Thorax, 1968, 23, 24

16 Sasahara, A. A., Stein, M., Simon, M., and Littmann, D., New England Fournal of Medicine, 1964, 270, 1075.

17 Sasahara, A. A., Belko, J. S., and Simpson, R. G., fournal of Nuclear Medicine, 1968, 9, 187.

18 Chernick, V., Lopez-Majano, V., Wagner, H. N., and Dutton, R. E., American Review of Respiratory Diseases, 1965, 92, 958.

19 Rogers, R. M., Kuhl, D. E., Hyde, R. W., and Mayock, R. L., Annals of Internal Medicine, 1967, 67, 947.

20 Garnett, E. S., Goddard, B. A., Machell, E. S., and MacLeod, W. M., Thorax, 1969, 24, 372.

21 Walker, R. H. S., and Provan, J. L., British Medical fournal, 1969, 3, 327 .

22 Beerel, F. R., Vance, J. W., Cordasco, E. M., Wende, R. W., and Toffolo, R. R., Archives of Internal Medicine, 1969, 124, 8. 
particles should encourage small departments to undertake lung scans.

Nuclear medicine is expanding and changing so rapidly that it is impossible to forecast which isotopes or what equipment will be in use in 10 or 20 years. Instant imaging devices such as gamma cameras and computer processing are likely to become more widespread. There is little doubt, however, that as scanning departments are set up in more district hospitals lung scanning in some form will be among the routine investigations most commonly performed.

\section{Glucagon and the Heart}

The presence of a contaminant which caused hyperglycaemia was noticed in samples of insulin within a year or two of its discovery. But for a long time glucagon remained a curiosity, though its origin from the alpha cells of the pancreas suggested that it might have a physiological function. Subsequent research has strengthened the view that it is indeed an essential hormone. ${ }^{1}$ Now the development of a sensitive immunoassay ${ }^{2}$ capable of distinguishing pancreatic glucagon from the gastrointestinal hyperglycaemic factor, enteroglucagon, which makes up $90 \%$ of serum activity, should put the matter beyond doubt.

The two best-known actions of glucagon are the promotion of hepatic synthesis of glucose from protein and the breakdown of glycogen. Thus it may be more important than adrenaline, and it has proved valuable in the treatment of hypoglycaemia. Like adrenaline it is thought to activate the adenyl cyclase enzyme system present in all nucleated cells. In the presence of magnesium this system converts adenosine triphosphate to cyclic adenosine $3^{\prime}-5^{\prime}$ monophosphate. The latter then reacts with phosphorlyase to convert glycogen to glucose-1-phosphate. ${ }^{3}$ Glucagon also has a number of other biochemical effects.

In $1960 \mathrm{~A}$. Farah and R. Tuttle ${ }^{4}$ showed that glucagon increased the strength and rate of contraction of the heart in experimental preparations from several animal species. Much work since then has confirmed these findings

1 Sokal, J. E., American fournal of Medicine, 1966, 41, 331.

2 Unger, R. H., Ohneda, A., Aguilar-Panada, E., and Eisentraut, A. M., fournal of Clinical Investigation, 1969, 48, 810.

Sutherland, E. W., Robison, G. A., and Butcher, R. W., Circulation, $1968,37,279$.

- Farah, A., and Tuttle, R., Fournal of Pharmacology and Experimental Therapeutics, 1960, 129, 49.

5 Regan, T. J., Lehan, P. H., Henneman, D. H., Behar, A., and Hellems, H. K., Fournal of Laboratory and Clinical Medicine, 1964, 63, 638 .

- Whitehouse, F. W., and James, T. N., Proceedings of the Society for Experimental Biology and Medicine, 1966, 122, 823

1 Lucchesi, B. R., Circulation Research, 1968, 22, 777.

s La Raia, P. J., Craig, R. J., and Reddy, W. J., American fournal of Cardiology, 1968, 21, 107.

- Glick, G., Parmley, W. W., Wechsler, A. S., and Sonnenblick, E. H., Circulation Research, 1968, 22, 789.

steiner, C., Wit, A. L., and Damato, A. N., American fournal of Cardiology, 1969, 23, 141.

11 Katz, R. L., Hinds, L., and Mills, C. J., British fournal of Anaesthesia, 1969, 41, 574 .

12 Parmley, W. W., Glick, G., and Sonnenblick, E. H., New England fournal of Medicine, 1968, 279, 12.

3 Klein, S. W., Morch, J. E., and Mahon, W. A.; Canadian Medical Association fournal, 1968, 98, 1161 14 Linhart, J. W., Barold, S. S., Cohen, L. S., Hildner, F. J., and

is Greenberg, B. H., Tsakiris, A. G., Moffit, E. A., and Frye, R. L., American fournal of Cardiology, $1969,23,116$.

16 Williams, J. F., jun., Childress, R. H., Chip, J. N., and Border, J. F. Circulation, 1969, 39, 38.

1 - Brogan, E., Kozonis, M. C., and Overy, D. C., Lancet, 1969, 1, 482.

C both in the experimental animals ${ }^{5-11}$ and in man. ${ }^{12-16}$ The hormone also facilitates atrioventricular conduction. ${ }^{10}$

In patients undergoing cardiac catheterization glucagon injected either directly into the pulmonary artery ${ }^{14} 15$ or intravenously ${ }^{16}$ produces a modest increase in heart rate and cardiac output, together with an increase in the rate of change of ventricular contraction. There may be some rise in the arterial systolic pressure and a fall in systemic vascular resistance, but left ventricular end-diastolic pressure either falls slightly or does not change. Improvement in myocardial performance is still possible in the fully digitalized heart. ${ }^{17}$ Though the action of glucagon varies in detail in different individuals, it begins about 1-3 minutes after injection, reaches a maximum in about 5 minutes, and lasts up to 20 minutes. It is less marked but more prolonged than the similar effects produced by catecholamines, and has the therapeutic advantage of not causing arrhythmias. There is sometimes a slight depression in serum potassium levels, and large doses tend to cause nausea.

The mechanism by which glucagon improves myocardial performance is not clear, though it would be tempting to propose an action on cardiac cyclic adenosine monophosphate. But when this has been measured the results have been conflicting. ${ }^{8}$ More work is needed to clarify its mode of action and its relation to other cardioactive drugs. In the meantime there is growing evidence that this striking property of glucagon is not merely of academic interest. A substance which does not increase myocardial irritability and is still active in the presence of digitalis and propranolol has obvious therapeutic possibilities. It has already been tried with some success in the treatment of resistant cardiac failure ${ }^{17}$ and has been suggested for use in hypotensive states following cardiac operations $^{12}$ and myocardial infarction. $A$ report on its administration to six patients is published in the B.M.F. this week (p. 663) by Drs. J. D. Eddy, E. T. O'Brien, and S. P. Singh. They describe a significant rise in blood pressure as a result of it. Glucagon might also have a place in antagonizing the myocardial depression produced by $\beta$-blocking agents, and its effect on atrioventricular conduction might be exploited in the relief of heart block. Its relatively transient action means that repeated intravenous administration will probably be required, and caution is necessary to ensure that it does not produce distressing nausea, serious falls in serum potassium, or rebound hypoglycaemia ${ }^{17}$ when treatment is stopped.

\section{Cystic Fibrosis Conference}

It is now over thirty years since cystic fibrosis was described, and during this time great advances in its understanding and treatment have been made, but it remains one of the major killing diseases of childhood and early adolescence. Last September the fifth international conference to be devoted to it was held in Cambridge, and speakers took the opportunity to review some of the work in progress on this not uncommon disease.

It is inherited in an autosomal recessive manner, and its incidence in the Caucasian population is about 1 in 2,000 2,500, with a lower incidence in Negro and Mongolian racial groups. Serum from affected children and also from heterozygote carriers of the disease causes disorganization and inhibition of ciliary beating in the gills of the fresh-water 